\title{
Trato digno en personas con discapacidad por lesión medular: enfoque de investigación ¿cualitativo o cuantitativo?
}

Dignified treatment of people with spínal cord injury disability: A qualitative or a quantitative approach?

\section{Sr. Editor:}

La legislación peruana reconoce la defensa de la persona humana y su dignidad como fin supremo de la sociedad y del Estado, así como la protección de la dignidad, mediante una adecuada calidad de atención en los servicios de salud $(1,2)$. La Organización Mundial de la Salud (OMS) define a la calidad en salud como "el conjunto de servicios diagnósticos y terapéuticos más adecuados para conseguir una atención sanitaria óptima; a fin de lograr un resultado con el mínimo riesgo de efectos y la máxima satisfacción del paciente" (3). Sin embargo, en nuestro medio, es común observar elevados niveles de insatisfacción de usuarios en la atención recibida en los servicios de salud pública $(4,5)$.

Entendiendo el trato digno como la forma actitudinal de la atención que se brinda al usuario, mediante habilidades de comunicación, amabilidad, respeto, justicia y atención oportuna (6), que según las leyes 26842 y 29414 , se establecen los derechos de las personas usuarias de los servicios de salud, leyes en las cuales se contempla que el paciente merece respeto a su autonomía, autodeterminación, privacidad, a recibir información suficiente, confidencialidad, confianza y comodidad necesaria, de manera que la atención le genere satisfacción (2).

El estudio de valores en una organización nos enfrenta a una problemática con respecto a la aplicación del método científico, específicamente en relación al uso de los enfoques cualitativo y cuantitativo. En el Instituto Nacional de Rehabilitación (INR), se está desarrollando un instrumento con el propósito de construir y validar una escala de percepción del trato digno del equipo multidisciplinario que atiende pacientes hospitalizados por lesión medular con paraplejia y cuadriplejia, este instrumento está basado en el cuestionario de Cairns y Coll (7), el cual ha sido rediseñado y adaptado culturalmente para obtener información sobre la trato digno; en su elaboración, se tomaron en cuenta conceptos de bioética, derechos humanos y salud pública, se ha recurrido a la opinión de jueces expertos a fin de obtener indicadores que apoyen la validez de contenido. Asimismo, se tiene planteado recoger datos que permitan optimizar la escala y obtener mayores evidencias de validez y confiabilidad.

El uso de instrumentos de medición en el proceso de investigación en valores es una forma objetiva de evaluar y obtener información, aunque debe tenerse en cuenta que los resultados contarán siempre con un margen de error, y que no podrá alcanzarse la tan ansiada objetividad, más aún cuando se aborda un tema tan complejo como el estudio de valores que de por sí, involucra muchos matices relacionados al contexto sociocultural. No obstante, y desde una perspectiva cualitativa mediante un proceso de triangulación metodológica y de datos (8), puede tenerse en cuenta un panorama más integral que permita abordar de manera apropiada dicha problemática utilizando conjuntamente con la metodología cuantitativa otros procedimientos como entrevistas a profundidad y focus groups, que nos permitan levantar juicios que reflejan de manera fidedigna la realidad. 
Lo cierto es que, al momento de analizar el debate metodológico de lo cualitativo frente a lo cuantitativo, Hernández et al (9), plantean el uso de métodos mixtos. Asimismo, Vasilachis (10), señala el carácter complementario de estos dos métodos y manifiesta que cada uno provee información que no solo es diferente desde el punto de vista del otro, sino que además funciona de manera fundamental para poder entender ambas perspectivas y que en muchas circunstancias son necesarios para una mutua verificación con distintos datos sobre el mismo fenómeno, que al ser contrastados conformen una explicación más integrada del problema en cuestión.

El estudio de valores plantea dos problemáticas, por un lado, la escasez de instrumentos de medición válidos y confiables, y por otro, el alto grado de subjetividad que se encuentra en la connotación que se hace del constructo de valores (11). Si bien existen instrumentos de medición a nivel internacional, hay carencia de instrumentos dirigidos a personas con discapacidad por lesión medular, considerada como una condición de salud crónica e irreversible.

Se asume el reto de comparar los resultados de ambos enfoques, cualitativo y cuantitativo, con evidencias de diversas fuentes e identificar los factores que interactúan en la relación entre el trabajador de salud y el paciente en su proceso de rehabilitación.

\section{Carmen Tataje Contreras ${ }^{1, a}$, Alicia Boluarte Carbajal ${ }^{1, b}$}

\section{REFERENCIAS BIBLIOGRÁFICAS}

1. Congreso Constituyente Democrático. Constitución Política del Perú 1993, artículo 1. Lima: Diario Oficial El Peruano; 19 de diciembre de 1993.

2. Comisión Técnica AD HOC para la Revisión del Anteproyecto de Reglamento de la Ley $\mathrm{N}^{\circ} 29414$. Reglamento de la Ley $\mathrm{N}^{\circ} 29414$, ley que establece los derechos de las personas usuarias de los servicios de salud. Lima: Ministerio de Salud; 2015.

3. World Health Organization. The principles of quality assurance. Copenhage: WHO; 2015.

4. Shimabuku R, Huicho L, Fernández D, Nakachi G, Maldonado R, Barrientos A. Niveles de insatisfacción del usuario externo en el Instituto Nacional de Salud del Niño de Lima, Perú. Rev Perú Med Exp Salud Pública. 2012; 29(4):483-89.

5. Rivera GT. Satisfacción de los usuarios a través de sus expectativas y percepciones en la atención médica. Diagnóstico. 2015; 54(1):5-9.

6. Pérez V, Pezoa G. ¿Qué es el "Trato Digno" para los pacientes?: Elementos globales que componen el trato digno. Santiago de Chile: Departamento de Estudios y Desarrollo; 2013.

7. Cairns D, Williams V, Victor C, Richards S, Le May A., Martin W, et al. The meaning and importance of dignified care: findings from a survey of health and social care professionals. BMC Geriatrics. 2013; 13:28. doi: 10.1186/1471-2318-13-28

8. Valbuena M, Morillo R, Salas D. Sistema de valores en las organizaciones. Omnia. 2006; 12(3):60-78.

9. Hernández R, Fernández C, Baptista P. Metodología de la investigación. Ciudad de México: McGrawHill; 2014.

10. Vasilachis I. Métodos cualitativos I: los problemas teóricos-epistemológicos. Buenos Aires:Centro Editor de América Latina; 1992.

11. Bolívar A. La evaluación de valores y actitudes. Madrid:Anaya; 2002. 